Revista Iberoamericana. Vol. LXIII, Núms. 178-179, Enero-Junio 1997; 47-60

\title{
FIGURACIONES DEL SUJETO MODERNO: BIOGRAFÍA, PLANTACIÓN Y MUERTE AL ALBOR DEL SIGLO XIX CUBANO ${ }^{1}$
}

POR

Agnes I. Lugo-Ortiz

Dartmouth College

\section{LOS COMIENZOS DEL GÉNERO BIOGRÁFICO EN CUBA}

Siglo de las grandes aventuras totalizadoras, el XIX no sólo vio en los mundos occidentales la intensificación privilegiada de la escritura novelística y de monumentales narrativas históricas sino también la emergencia de los grandes relatos biográficos. Desde la imponente Life of Johnson de John Boswell [1791], pasando por el elusivo Facundo de Sarmiento (1845) y las voluntades heroicas de Jules Michelet en su exaltación de Jeanne d'Arc (Histoire du France, 1841), de Thomas Carlyle en su On Heroes, Hero-Worship and the Heroic in History (1841) y de Emerson en su Representative Men (1850), hasta las extraordinarias crónicas biográficas de José Martí en sus Escenas norteamericanas (durante los años ochenta), el género parece haberse constituído a lo largo del siglo en uno de los principales escenarios en donde ensayar el drama del saber moderno. Al interior de sus múltiples y escurridizas inflexiones estéticas se encuentra una estructura formal en la que se deslinda a un sujeto cognoscente de su objeto, guiada por el impulso inequívoco hacia la producción de una verdad asumida como preexistente y acequible, y en cuya aparente rigidez rítmica pretende demarcase a un sujeto singular en cuanto idea clara y distinta.

Pensar la escritura biográfica en la Cuba del siglo XIX es pensar una instancia específica en la articulación de lo biográfico. Los inicios del género se sitúan en el contexto de las primeras instituciones modernizadoras asociadas, no sin paradojas, al desarrollo del sistema de la plantación azucarera esclavista en la isla a partir de finales del siglo XVIII. No bien incorporada la primera Sociedad Económica de Amigos del País (o Sociedad Patriótica, como se le conoció primeramente) en 1792, ya su primer socio y promotor, el gobernador don Luis de las Casas, sugiere que se convoque un concurso para premiar el texto

\footnotetext{
${ }^{1}$ Vaya mi agradecimiento a Ivette Hernández, Rafael Rojas y Juan Carlos Quintero por su siempre generosa disposición a conversar sobre los temas que aquí me ocupan. Ivette leyó cuidadosamente una primera versión del ensayo haciendo observaciones útiles. Juan Carlos iluminó muchos de mis puntos ciegos respecto a la concepción de la muerte en el orden de los Orishas. Los ensayos de Rafael han sido imprescindibles en la formulación de las líneas de análisis que aquí bosquejo. A Diane Miliotes, como siempre, le debo la presencia amorosamente cotidiana y el seguir paso a paso y con implacabilidad crítica el desarrollo de estas ideas. Las insuficencias del resultado final, claro está, son únicamente responsabilidad mía.
} 
en que mejor se demuestre, quales son los quatro sugetos de cualquier estado ó condición, que por sus buenas obras sean mas acreedores á la gratitud de toda la isla de Cuba en comun, ó bien en particular de esta ciudad de la Havana, para erigirles otras tantas Estátuas en el paseo público extra-muros de ella; excluyendo de estos honoríficos monumentos á los que actualmente viven, para cerrar toda puerta á la torpe adulación. ${ }^{2}$

La convocatoria coincide con otras tres dirigidas a estimular mediante premiación las memorias que mejor discutan "el estado actual de la agricultura y medios para desarrollarla", la construcción de "caminos y los beneficios que resultarán de ellos" así como un premio para el "que más y mejores ladrillos tejas hubiera vendido al público" (Memorias 1793, 7273). Me detengo en estos pormenores para subrayar varios aspectos significativos sobre el momento de incepción del género.

El primer estímulo biográfico en la isla está orgánicamente vinculado a una voluntad protomoderna de sociedad y al deseo limitado, pero no por ello menos real, de forjar un dominio público. No obstante ir investida con los signos externos de una aristocracia en apogeo (e.g. su obsesión por obtener títulos de nobleza) y mantenida por la explotación descarnada de miles de esclavos africanos, la oligarquía cubana recién convertida en sacarocracia hacia el último tercio del siglo XVIII - para usar el término acuñado por Moreno Fraginals - desplegó en su momento de emergencia ambiciones e ímpetus de una burguesía en ascenso. No sólo se trató de procurar agresivamente una modernización tecnológica y de renovar el instrumental epistemológico vigente hasta aquel entonces (e.g. el desplazamiento de los paradigmas escolásticos por los de las ciencias naturales) sino también de maximizar los usos del andamiaje simbólico en la rearticulación de su ethos de clase. $^{3}$ Frente al horizonte promisorio del azúcar, las elites cubanas fomentaron la importación de nuevas maquinarias para incrementar el rendimiento de la plantación, impulsaron reformas curriculares abriéndole paso a la enseñanza de la química y de la física experimentales con el fin de racionalizar científicamente los principios productivos, insistieron en la reorganización de la instrucción primaria y en el establecimiento de programas públicos de higiene, y estimularon la remuneración de investigaciones conducentes

${ }^{2}$ Papel Periódico de la Havana, núm. 87, año de 1793. Véanse también las Actas de la Sociedad Patriótica (Junta Ordinaria del 17 de octubre de 1793; 94) y las Memorias de la Sociedad de 1793, 23-24; y las de 1794, 58-59.

3 "Y es que el plantador cubano de la época se expresa en términos burgueses. Eran productores de mercancías con destino al mercado mundial, y por tanto pensaban como burgueses europeos. Por su actitud burguesa están revolucionando su cultura al revolucionar sus instrumentos de producción, como están revolucionando su sistema de producción al revolucionar su cultura. Su idea del progreso está unida a la del saber científico. Hacen viajes de investigación a las colonias inglesas. Dan ocupación a todos los técnicos franceses que vienen huyendo de la sublevación de esclavos de Saint Domingue. En 1790 tienen máquinas de vapor funcionando en La Habana, y en 1794 encargan una de Watt, de doble efecto, para instalarla en un ingenio cubano. La experiencia tiene lugar dos años después en el ingenio «Seybabo», en las cercanías de la ciudad de La Habana: es la primera del mundo aplicada a la producción azucarera y, sin duda, la primera del imperio español" (Moreno, Cubal España 149). Imprescindible para la comprensión del desarrollo del sistema de plantación en la isla es también el ya clásico estudio de Moreno, El ingenio. El complejo económico social cubano del azúcar. Importante para una panorámica de la historia de las ideas en Cuba durante el siglo XIX es el texto de Medardo Vitier, Las ideas en Cuba. 
a adelantar el nuevo ordenamiento socio-económico. Es dentro de estas coordenadas -y animados por el principio de premiar el mérito a través de la competencia—que se insertan los concursos auspiciados por la Sociedad Patriótica.

En las primeras convocatorias se hace patente una voluntad de instrumentalizar la reflexión al servicio de la producción comercial del azúcar: premiar el pensamiento analítico sobre "el estado actual de la agricultura" (que en los códigos de la época vino a ser mayormente sinónimo de producción azucarera) con miras a procurar su mejor desarrollo; premiar el diseño de nuevas vías de comunicación ("los caminos") para facilitar su transporte comercial; premiar la elaboración y distribución de materiales de construcción fundamentales a la infraestructura económica ("los ladrillos tejas"). En el interior de esa activa maquinaria productora de saberes también se engrana, como tecnología privilegiada para la configuración del sujeto a regir el nuevo ordenamiento social, la escritura biográfica. Analizar los resortes de esa máquina de producción simbólica en su momento de emergencia es el propósito del presente ensayo.

\section{UN TEXTO FUNDADOR}

Los términos de la convocatoria publicada en el Papel Periódico de la Havana, anteriormente citada, posicionan lo biográfico en función de una idea monumental de la historia, así como en relación al deseo de estructurar simbólicamente el espacio colectivo. Desde su dimensión más visible se trata, literalmente y sin sutilezas, de justificar la erección de monumentos; de explicar biográficamente la presencia decorativa de unas estatuas - con su fijeza de piedra - en el paseo público que circundaba las murallas de la ciudad. En el decorado citadino debían visibilizarse los contenidos monumentales de una historia. Mediante el recuento de una vida ejemplar, útil y meritoria, el texto biográfico estaba llamado a narrativizar, a movilizar temporal, verbalmente, el espejismo de presencia viva producido por la figura tridimensional inerte. ${ }^{4}$ En ese sueño de ornamentación urbana, la ciudad debía devenir simultáneamente texto histórico y texto pedagógico. ${ }^{5}$ No sólo se trataba de personificar para la sacarocracia ascendente la imagen de un pasado ofrecido como propio, sino también la de una virtualidad: la posibilidad de un devenir tan grandioso como el carácter ejemplar de los mayores que le precedieron; figura especular y espectacular a ser exhibida ante la mirada respetuosa de unos otros (esclavos y plebeyos) imaginados sin historia. ${ }^{6}$ Es esta doble funcionalidad (admiración/imitación; admiración/reverencia) lo

\footnotetext{
4 "Others in museums pass them by/but I, I/am drawn like a maggot to meat/by their pupilless eyes/ and their putrifying individuality". John Updike, "Roman Portrait Busts".

5 "Paseo público, yermo, antiguo teatro de lujo y vanidad, tú serás convertido en un jardín ameno y delicioso, aun más fecundo en virtudes cívicas que en las bellas producciones de Flora y Pomona". Tomás Romay, "Oración gratulatoria. Discurso de Gracias, por habérsele conferido el premio. Pronunciado por el Dr. Tomás Romay en la junta ordinaria de la Sociedad el día 21 de julio de 1794". Obras Completas, vol. II; 216.

${ }^{6}$ En un sentido estricto ese impulso de monumentalidad corresponde a lo descrito por Nietzsche en su The Use and Abuse of History al discutir lo que él entiende son los tres grandes tipos de modos y usos historiográficos. En contraste con la historiografia anticuaria (fundamentalmente guiada por un deseo de reverencia) y la crítica (producto de una instancia de opresión y dirigida al juicio y condena
} 
que se ejemplifica en la producción y recepción del discurso laureado por la Sociedad Patriótica en 1794 y escrito por don Tomás Romay —(1769-1849) médico destacado, propagandista militante de la inmigración blanca, uno de los más activos miembros de la corporación desde sus inicios y su presidente hacia 1844. El texto podría leerse como fundador del gesto biográfico en Cuba, y su funcionalidad social apunta hacia algunos de los ejes constitutivos en las nociones de sujeto político formuladas en la isla a lo largo de la primera mitad del siglo XIX.

El texto de Romay comienza enumerando los objetivos que lo guían: "Premiar las virtudes cívicas de nuestros mayores; excitar su posteridad á imitarlas; estimular nuestros ingénios á merecer los sufragios de un Cuerpo sábio y benéfico [...]". ${ }^{7}$ De entrada se trata de producir la imagen de un pasado digno de reconocimiento en la celebración de sus virtudes civicas y de ofrecerlo como modelo a ser imitado en el presente. Junto a ello también se enuncia el deseo de afirmar el mérito de la individualidad/autoría propia, convirtiéndose a sí mismo — como para cerrar un círculo — en objeto de reconocimiento a través de un acto escritural de gratitud. En la selección de las cuatro figuras presentadas por Romay como los mayores benefactores de la sociedad cubana (Cristóbal Colón, Juan Francisco Caraballo, Martín Calvo de Arrieta y Carlos III) se codifica el modelo de sujeto protociudadano deseado por una fracción de la ascendente sacarocracia, sus fundamentos epistemológicos y éticos, el tempo histórico de su surgimiento, así como sus zonas límites.

\section{LA FIGURACIÓN DEL SUJETO: SU RACIONALIDAD HISTÓRICA}

En el texto de Romay los recortes ideológicos y estéticos de Cristóbal Colón y de Carlos III marcan los polos de un tiempo histórico: tiempo de origen y tiempo de iniciación. Ambos afiliados a la temporalidad histórica de España. De Colón, el Descubrimiento, representado en su narrativa no como una empresa opacada por la violencia militar (categoría esta última prácticamente ausente del discurso de Romay y de su noción civil del mérito) sino como una gesta de paz. En un contraste sutil con lo que superficialmente podría parecer un silenciamiento de los horrores de la Conquista y de la Colonización, Colón es representado como "el más humano de los conquistadores" que "imponía el suave y leve yugo" sobre los indígenas, sin que se "percibiesen el horrísono estallido del cañon, ni los agudos filos del acero" (194). Colón, figura antitiránica por excelencia "que solicitó ponernos, no entre las cadenas de un déspota inexorable, sino baxo la protección de una madre tierna y benéfica; de la incomparable Isabel de Castilla" (194).

del pasado), la historiografía monumental es aquélla que se despliega en un momento en que la voluntad de acción requiere modelos a imitar. No se monumentaliza el pasado para la parálisis o la veneración sino para garantizar el constituirse en sujeto de dominio en el presente (el pasado como fundamento de una posibilidad viva, activa, actual). Obviamente, en una misma coyuntura histórica lo que se piensa monumental para ciertos sectores sociales se quiere anticuario (objeto de reverencia) para otros que no están supuestos a ser agentes de la historia, a tener voluntad de hacer y ser.

${ }^{7}$ Tomás Romay, Discurso Premiado por la Sociedad Patriótica de la Havana, en Junta que Celebró el Día 24 de Julio del Año 1794. Obras Completas, vol. II; 189. De este discurso se hicieron otras dos ediciones. La tercera, de 1845 y a la que Romay hizo cambio notables, está también recogida en la misma edición de sus obras completas (201-214). 
Pero ese tiempo de origen, marcado por impulsos generosos y moderados de paz en el seno maternal de una figura monárquica benévola, está también marcado por una voluntad antiautoritaria de saber. El heroísmo de Colón es un heroísmo ilustrado, vertebrado por el cuestionamiento científico y moderno de las verdades heredadas; un heroísmo intelectual de corte racionalista:

Si por espacio de 45 años no se hubiese preparado á esta época dichosa, ilustrandose con el profundo y constante estúdio de las matemáticas; sacudiendo el yugo de los más respetables despotas del entendimiento humano [...] si Colon en fin, antes de superar los grandes obstáculos con que la naturaleza nos habia separado del antiguo continente, no hubiese triunfado de los errores y preocupaciones de su siglo, de la envídia y felonía de los hombres; yo temería consagrar á la audácia, ó felíz casualidad aquellos sufrágios dignos solamente de un valor intrépido y reflexivo, de un resultado previsto, de un cálculo científico, de unas virtudes las más heróicas (191).

El momento del origen, personificado en la figura de Colón, no es uno atravesado ni por la violencia ni por la fatalidad o el destino. Por el contrario, es un origen civil generado por un espíritu moderno de saber y guiado por el conocimiento matemático. No es el resultado de un azar sino del cálculo.

Si el origen (Colón) está estructurado por un moderno, aunque restringido, heroísmo de la reflexión crítica, el momento de la iniciación histórica (cifrado en la figura de Carlos III) se postula como el de la entrada de Cuba al orden moderno del librecambio. Carlos rompió

las antigüas y gravosas cadenas de nuestro comércio, lo franqueó á los principales puertos de Europa: suprimió una multitud de derechos que aprisionaban la indústria y enervaban la actividad, y con sola una accion nos hizo á todos felices, proscribiendo aquél detestable monopólio que enriquecía á quatro particulares con detrimento de toda la Colónia. Esta es la época de igualdad en nuestras fortunas: este es el fecundo cauce de donde han manado nuestras prosperidades. De aquí el fomento de trescientos y mas Ingenios de azucar: de aquí la fábrica de esos edifícios que decoran la Havana, honran las artes, protegen la humanidad. De aquí ... seria interminable si pretendiera referirlas por menor. De aquí la feliz metamórfosis que ha convertido nuestra pátria de un caserio informe y mísero, en una Ciudad culta brillante y populosa (199).

La serie de reformas promulgadas para la isla después de la ocupación inglesa de La Habana en 1762 se convirtieron, en los discursos patricios de la primera mitad del siglo XIX, en hito privilegiado para fechar la entrada de Cuba a la vida histórica. A Carlos no se lo celebra en virtud de su autoridad real, sino en virtud de la instrumentalización moderna de esa autoridad. En cuanto rey, Carlos III hubiese carecido de mérito si esa realeza no hubiera sido puesta al servicio de una "utilidad pública", definida ésta a lo largo de intereses de tipo burgués: la libre competencia, la erosión del mercantilismo, la liberalización del sistema de gravámenes. Romay no lo dice, pero es gracias a esa liberalización comercial que se puede intensificar el tráfico de esclavos en la isla con el propósito de resolver lo que al decir de la época se llamó la "escasez de brazos". De ello dependieron las condiciones básicas para el desarrollo de la plantación y para el definitivo impulso de la producción azucarera cubana 
a partir de 1792, a raíz de la revolución de esclavos en Haití y la subsecuente caída de su sitial como el primer suplidor de azúcar de caña en el mundo. De ello dependió, en última instancia, "la felicidad" y la existencia misma de la sacarocracia.

Lejos de un criterio duro de autoridad, lo que se genera conceptualmente en el texto de Romay es la valoración del hacer individual frente al horizonte de la "utilidad pública". Carlos no es celebrado apriorísticamente en cuanto rey sino analíticamente en cuanto agente "útil".

Prescindiendo al hombre del esplendor de la cuna, de las acciones de sus progenitores, de sus dignidades y riquezas, y de todo lo que no es suyo, segun la expresion de Séneca, le admira solamente y le venera quando lo exigen sus própias obras (190).

La convocatoria misma del concurso, en la que se dictaminaba que no era necesario hacer distingos de "estado ó condición" al reconocer el mérito de los sujetos elogiados, admite y estimula cierta apertura en el orden de los valores. Una apertura que no deja de tener un sesgo nivelador potencialmente peligroso ante el horizonte inmediato de la Revolución Francesa. En un texto plagado por el uso de una retórica liberal e ilustrada virtud, república, ciudadania, equidad, libertad, utilidad-el riesgo se modera privilegiando la figura de Carlos por sobre todas las demás, jerarquizando la yuxtaposición sospechosa (i.e. es Carlos quien culmina y cierra el texto) y celebrando la actitud de un monarca cuya ilustración y virtud lo llevará a apreciar "ver colocada su efígie entre unos vasallos amantes de la humanidad y de las virtudes cívicas" (191).

En la narrativa de Romay, el tempo de la historia cubana aparece como el de una plena modernidad. Sus orígenes se fundan en las hazañas civiles del espíritu científico y su vida histórica en los principios (recortados, sin duda) de la economía política. A esa estructuración regida por el despliegue de una racionalidad económico/científica se sumarán, como guía para una deseada reconfiguración del sujeto a dirigir el nuevo ordenamiento social, las consideraciones de una razón moral.

\section{LA FIGURACIÓN DEL SUJETO: LA RAZÓN MORAL Y SUS LÍMTTES}

De Juan Francisco Caraballo(sevillano, ¿?-1718)) y Martín Calvo de Arrieta (habanero, 1583-1669) se celebran sus virtudes cívicas. Al primero se lo reconoce por haber fundado, con su propio peculio, una escuela gratuita de primeras letras y el Hospital de Belén. Al segundo se lo exalta por haber dejado en testamento - con generosidad de padre - fondos para dotar anualmente a cinco huérfanas pobres (de modo que pudieran casarse evitando ser sepultadas "para siempre en un claustro, ó prostituir su cuerpo á un torpe lucro" (196)). Educación, higiene/salud, regimentación de lo sexual (femenino) a través del matrimonio, la procreación y la familia son los proyectos reconocidos en la iniciativa individual de Caraballo y Arrieta. En ambos casos, el mérito mayor se funda en haber puesto la riqueza privada al servicio protector de un bien público; de funcionalizar el capital a favor de la consolidación de un proyecto de sociedad.

Cual si se buscase atenuar las consecuencias del impulso egoísta y potencialmente antisocial de una razón rígidamente pragmática (guiada exclusivamente por el interés económico), en el texto de Romay se propone, paralelamente, un sujeto constituido en la 
práctica de la virtud ciudadana como actualización de una ética del desprendimiento. ${ }^{8}$ Esa virtud entraña, a su vez, la exigencia autoritaria de ocupar el lugar del padre; el imperativo de desplegar la potencialidad del ser (de dar de sí) en el acto de la reproducción biológica. Sin sutilezas, se trata de reorganizar al nuevo sujeto de poder en una doble tarea genealógica: padre/gestor de sus hijos, padre/gestor de su sociedad. Tanto la (re)productividad del cuerpo, como la(re)productividad socialmente provechosa del capital son postuladas como demandas de la virtud ciudadana. En un giro crítico e hiperprescriptivo, las imprecaciones iracundas de Romay son contundentes:

\begin{abstract}
Vosotros, egoistas insensibles, que reconcentrais en vosotros mismos vuestro ser y vuestros bienes: entes quiméricos y ridículos que temeis haceros menos felices, dividiendo con otros vuestras prosperidades: célibes profanos, que cometeis tantos parricídios quantos hijos rehusais engendrar; estremeceos, y pedid á la tierra os abisme en sus entrañas á vista de ese rasgo dictado por las virtudes sociales (196).
\end{abstract}

El modelo de sujeto patriarcal llamado a dirigir y articular el nuevo ordenamiento socio-económico entrelaza indisolublemente la práctica instrumental (egoísta) de la razón y la idea secular y modernizada de la antigua virtud cívica. Aún más, podría decirse que en Cuba el género biográfico mismo en su momento de emergencia se constituye precisamente en la voluntad formal de armonizar esas dos racionalidades. Todo ello dentro de la lógica estructural y retórica del pater familias.

Esa conciliación ideológica y estética que el género pretende lograr entre razón instrumental y razón moral, e inevitablemente recorrida por tensiones y zonas de imposibilidad, es lo que se le propone a las elites ascendentes como imagen deseable para sí. La inscripción diseñada por Romay para la estatua de Martín Calvo de Arrieta (a quien llama "Hombre, Padre, Ciudadano el más perfecto", 196) lo enuncia de forma inequívoca:

\footnotetext{
Don Martín Calvo de Arrieta

Natural y vecino de la Havana,

Le dexó un fondo de 102 mil pesos

Para el dote anual de cinco doncellas:

Pobres, bendecidle; Ricos, imitadle (200).
}

"Pobres bendecidle: Ricos imitadle". La sentencia ordena las posiciones de sujeto a ser ocupadas por distintos sectores sociales en el interior de la formalización biográfica. En el acto compartido del reconocimiento, pobres y ricos debían hallar una zona de pertenencia

\footnotetext{
${ }^{8}$ Fundamental para la discusión que aquí desarrollo han sido los inteligentes ensayos de Rafael Rojas, "Viaje a la semilla: Instituciones de la anti-modernidad cubana" y "La otra moral de la teleología cubana". Sus ensayos establecen un dialógo polémico con la interpretación de la historia intelectual cubana avanzada en el libro de Cintio Vitier. Para el debate sobre las tensiones entre razón moral y razón instrumental en Cuba, véanse Rojas, "La otra moral ...", "El epitafio de Saco", Vitier, Arango y Torres-Cuevas. Para una discusión de las tensiones entre los imperativos comunitarios generados por la modernidad social y la moral utilitaria/egoísta del capitalismo, véase Miller. Fundamentales son igualmente Weber y Habermas.
} 
común, el espacio de una memoria compartida. De ella debía emanar la valoración de una restringida noción de lo público/civil como primera fuente de identidad socio-cultural (aún no programáticamente nacional) de los sectores blancos en Cuba, independientemente de su lugar de nacimiento o posición social. No sorprende entonces que poco después de que Romay recibiera el laudo, la Sociedad Patriótica pasase a considerar su publicación y futuros usos como lectura obligatoria en las escuelas gratuitas instituidas por la corporación mayormente para blancos pobres - en el afán de centralizar bajo su tutela un sistema de enseñanza pública:

[...] que en las Escuelas gratuitas que subsistan bajo los auspicios de la Sociedad se establecería que los Alumnos dedicasen con cierta preferencia á la lectura del mencionado Discurso con la idea de que aquellas criaturas viesen desde que le apuntaba la vida, quienes eran los hombres que debian mirar como bienhechores á la Patria, y se les imprimiese en sus tiernos corazones que la Beneficencia es una de las virtudes sociales mas dignas de aprecio $[\ldots] .^{9}$

Los modos de apropiación institucional intensifican la orientación pedagógica y moralizadora de lo biográfico pero también subrayan su funcionalidad diferencial: reconocimiento admirativo y agradecido del subalterno, reconocimiento imitativo (autorreflexivo) de las elites. De esa economía de valoraciones estaban excluidos, en cuanto seres considerados como el afuera de la cultura - y en consecuencia infrahumanos- los miles de esclavos africanos sin cuyo trabajo era impensable la forja del nuevo orden social. La esclavitud, vértebra de la plantación, sería el abismo insalvable para la ejecución de un diseño expansivamente moderno de sociedad, el dilema económico mayor de la sacarocracia a lo largo de la primera mitad del siglo XIX, su camisa de fuerza en términos políticos y la escisión más profunda ante cualquier asomo de voluntad nacional. Ella constituyó el límite más duro en el interior del proyecto modernizador adelantado por las fracciones más críticas e ilustradas de la oligarquía azucarera, su zona de imposibilidad más punzante. ${ }^{10}$

\footnotetext{
${ }^{9}$ Actas de la Sociedad Patriótica, Junta del 24 de julio de 1794; 202-203. Merece recordarse que el afán de la Sociedad por centralizar la administración de la educación se esgrimió contra las pequeñas escuelas mayormente de niñas y dirigidas, en un número significativo, por mujeres de color (al decir de la época). Antonio Bachiller y Morales, en un texto fundamental para el estudio de la cultura cubana del siglo XIX, se hace eco del celo segregatorio desplegado por la Sociedad en sus primeras campañas educativas: "Vióse entonces el fenómeno de ser muchas escuelas, principalmente de niñas, dirigidas por personas de color: la raza más envilecida y la más ignorante, enseñar a la caucásica. Esta rareza producía otra, que desde luego procuró destruir la Sociedad Económica: la confusión en un mismo recinto de todos colores y castas, fomentando de esa manera desde la infancia ese elemento de corrupción moral que trae de suyo la inevitable familiaridad de los jóvenes de diversas condiciones en los países de esclavos" (Bachiller y Morales 7).

${ }^{10}$ Para 1801, en un informe presentado a la Sociedad Patriótica por Fray Manuel de Quesada, queda claramente estipulada la exclusión de los esclavos de los modos de subjetivización diseñados en la letra, situándolos en la única temporalidad que se les reconocía, la del presente eterno de la producción: "Que se destierre el abuso del tiempo que hacen algunos maestros dedicándosle a enseñar a leer y escribir a los esclavos" (Bachiller, Apuntes vol. I, 23). Sobre el debate plantación/esclavitud/ nación en Cuba véanse: Benítez Rojo, Cepero Bonilla, Knight, Moreno Fraginals, "Desgarramiento azucarero e integración nacional"; y Scott.
} 


\section{LA TRADICIÓN BIOGRÁFICA Y LA MUERTE}

El texto de Romay es emblemático del tipo de producción biográfica que se generó y predominó en el seno de las élites cubanas a lo largo de la primera mitad del siglo XIX. Desde sus primeras juntas, la Sociedad Patriótica institucionalizó en sus sesiones la lectura de elogios, en su mayoría fúnebres, algunos de los cuales - dependiendo de la importancia $\mathrm{u}$ oficialidad del individuo en cuestión - fueron posteriormente publicados en periódicos o folletos (Memorias de la Sociedad 1793, 184). La lectura de esos elogios se convirtió en una suerte de ritual, por lo general íntimo, en el que a algún miembro de la corporación le era asignada la tarea de hacer el recuento de la vida pública del compañero fallecido, relatando los hechos de su virtudes cívicas. Estos se fueron registrando en las Memorias de la Sociedad, configurándose en ellas lo que se podría leer como una necrópolis simbólica habitada por las más prominentes figuras patricias de la época. Al igual que en la convocatoria del concurso ganado por Romay, en la que explícitamente se excluía a los vivos como material de celebración, los rituales instituídos por la Sociedad Patriótica también prescribían para lo biográfico una relación de inmediatez respecto a la muerte.

La conciencia moderna, en la vertiente de una racionalidad científica, ha desterrado progresivamente a los muertos de su círculo de intercambios. Según lo ha discutido Jean Baudrillard, para ella los muertos - ya convertidos en cadáveres - no existen:

Son arrojados fuera de la circulación simbólica del grupo. No son seres protagonistas, compañeros dignos del intercambio, y se les hace verlo muy bien al proscribirlos cada vez más lejos del grupo de los vivos, de la intimidad doméstica al cementerio, primer reagrupamiento todavía en el corazón del pueblo o de la ciudad, luego, primer guetto y prefiguración de todos los guettos futuros, arrojados cada vez más del centro hacia la periferia, y finalmente a ninguna parte, como en las ciudades nuevas o metrópolis contemporáneas, donde nada ha sido previsto para los muertos, ni en el espacio físico ni en el mental (Baudrillard 145).

En la reflexión de Baudrillard, los muertos son los primeros exiliados del mundo moderno, y proporcional a ese exilio es que ha crecido el concepto y valor cultural de la inmortalidad.

Porque el más allá de la muerte, ese estatuto eminente que es la marca del "alma" y de las espiritualidades "superiores", no es más que la moraleja que encubre la extradición de los muertos y la ruptura del intercambio simbólico con ellos. Cuando los muertos están ahí, diferentes pero vivos en múltiples intercambios, no necesitan ser inmortales, no hace falta que lo sean, porque esa cualidad fantástica rompería toda reciprocidad. Sólo a medida que son excluídos por los vivos se vuelven tranquilamente inmortales, y esa supervivencia idealizada no es sino la marca de su exilio social (Baudrillard 147).

No deja de ser notable que Tomás Romay, fundador del gesto biográfico público en Cuba, fuera también, en una guerra contra la muerte, el mayor promotor de programas de higiene en la isla durante las primeras décadas del siglo XIX. Éstos incluyeron desde estudios sobre la fiebre amarilla (1798), campañas para el fomento de la vacuna (a partir de 1804), su infatigable lucha contra los estragos de la epidemia del cólera-morbo en 1833 , 
hasta la primera propuesta formulada en Cuba para poner un cementerio en las afueras de la ciudad de La Habana (1802) (Montoro 19). La emergencia de lo biográfico aparece emblemáticamente amalgamada, en la figura de Romay, dentro del universo de una lucha constante por cercar, dominar o suprimir la muerte.

Tanto el "Discurso sobre los cuatro sugetos ..." como los rituales fúnebres de la Sociedad Patriótica asumen una misma actitud utilitaria respecto a los muertos. Los muertos tienen un uso modélico particular. Mediante el relato de sus vidas (en tanto ya acabadas) se genera un beneficio, una ganancia simbólica y política: la generación imaginaria y potencialmente virtual de sujetos - de poder a través de la imitación; subalternos por una gratitud reverente- - y la articulación de una memoria histórica monumental/utilizable (la construcción de un pasado mediante el cual una comunidad se constituye en el presente y se proyecta hacia el porvenir). Es de la elaboración de un valor de uso que depende el acceso de los muertos a la inmortalidad, su cambio o transformación en entes inmortales. O dicho de otro modo: no hay inmortalidad si no se produce un surplus utilizable, invertible simbólicamente en la regimentación de lo social.

Pero ese valor de uso producido en el elogio biográfico y que posibilita —mediante el consumo ritual comunitario - la entrada del muerto a la esfera trascendente e inmaterial de la inmortalidad, presupone a su vez una afirmación radical de la muerte como vacío. Al muerto se lo puede usar y celebrar porque se lo conceptúa como una entidad incapaz de respuesta ("nadie está allí para asumir el enunciado"). ${ }^{11}$ Es esto lo que se sugiere en la convocatoria del concurso ganado por Romay ("cerrar la puerta a la torpe adulación" para evitar una respuesta de reciprocidad individualmente provechosa hacia el vivo) y lo que el propio Romay enuncia de modo explícito en la dedicatoria que le hace al ya fallecido gobernador Luis de las Casas de la segunda edición de su discurso: "cuando ya nada espera de su benevolencia ni teme de su poder" (202). Vacío de la presencia, de la voz, de la (inter)acción, el exilio del muerto al mundo del no ser es la condición de posibilidad para la funcionalización simbólica y política de la muerte en lo biográfico.

El muerto no es el compañero admitido a una relación recíproca dentro de las redes de un intercambio material o simbólico. Sobre él -y no con él- se establecería otro tipo de economía dirigida a consolidar los intercambios entre vivos. Siguiendo a Michel de Certeau en sus reflexiones sobre la escritura de la historia, se diría que en esta coyuntura del hacer biográfico:

El objeto que circula [por el discurso] no es sino el ausente, mientras que su sentido es ser un lenguaje entre el narrador y sus lectores, es decir entre presentes. La cosa comunicada opera la comunicación de un grupo consigo mismo por medio de esa remisión a un tercero ausente que es su pasado. El muerto es la figura objetiva de un intercambio entre vivos (de Certeau 66). ${ }^{12}$

\footnotetext{
"Roland Barthes, "El discurso de la historia".

${ }^{12}$ En este sentido podría decirse que el valor del muerto aparece regido por la lógica de la mercancía y que exhibe su carácter dual: valor de uso y valor de cambio. En el impulso modernizador ni la muerte escapa de la voracidad de una comodificación implacable. Véase el ya clásico análisis de la mercancía en Marx 43-102.
} 
El muerto es el canal vacío que se ha dado el discurso biográfico como vía de circulación. Allí, la ficción de una inmortalidad —como expresión de una "supervivencia idealizada"- se convierte en vehículo para la consolidación de una comunidad presente y para la instauración, con el peso de una garantía monumental e inmaterial, de la forma de su devenir. En las interpelaciones y convocatorias construidas en torno al muerto - vacío impostado por sueños modernizadores - la sacarocracia cubana habría de reconocer e instituir un rostro asumido como propio.

\section{Coda: La fiesta de los MUERTOS}

La concepción moderna de la muerte que vertebra la emergencia de una tradición biográfica entre las élites cubanas al albor del siglo XIX despliega hacia los muertos un interés instrumental. Respecto a ellos se asume una actitud utilitaria y cosificadora dirigida a maximizar su rendimiento simbólico. Por el contrario, y de forma paralela, en el mundo de la plantación, entre los grupos subyugados por la esclavitud, se irían cociendo y arraigando formas culturales sincréticas de gran complejidad en las que los muertos seguirían siendo compañeros íntimos de los vivos, partícipes activos en un juego de reciprocidades e intercambios.

La plantación es un mundo arquetípica y materialmente estructurado por la muerte. Desde sus orígenes históricos, la figura misma del esclavo ha estado vinculada a la idea de una muerte pospuesta, a la de una vida prestada de la cual no se es realmente dueño. Los primeros esclavos eran prisioneros de guerra a quienes se les había conmutado una sentencia de muerte por la de una vida de trabajos forzados. Aquéllos a quienes se libraba de la muerte eran ofrecidos en venta al mejor postor. El amo/comprador, dentro de aquella óptica, pagaba una suerte de "rescate" por la vida del prisionero, y en virtud de ello era que esa vida le pertenecía. Es a partir de ahí, según lo ha analizado Orlando Patterson, que al esclavo no se le reconociera una existencia social autónoma a la del amo. Ante los ojos del poder se trataba de una entidad carente del derecho a la vida propia, de un "muerto social" (Patterson 5). ${ }^{13}$

El régimen de dominio bajo la esclavitud se apoya en tecnologías de subyugación, no de subjetivización. Al esclavo no se lo interpela en una compleja red de enunciados que lo constituyan, mediante un intercambio comunicativo desigual, en sujeto subordinado (de ahí la importancia de que no aprendiera a leer ni a escribir), sino a través de mecanismos permanentes de coerción. La amenaza de la tortura o de la muerte se convierte en el recurso obligado para garantizar su actividad social productiva. Que su cuerpo no le pertenecía era el incesante recordatorio emitido por el látigo, el cepo o el mastín del rancheador. Juan Francisco Manzano, en una extraordinaria carta a su mecenas Domingo Delmonte, lo diría

\footnotetext{
${ }^{13}$ Debe aclararse que esta "muerte social" de ninguna manera significa la sumisión sin resistencias por parte del esclavo o que éste no construyera - como esfera propia- formas de organización social alternas a las pautadas por el poder. El término apunta, más bien, a las presuposiciones filosóficas de ese particular régimen de subordinación. El término tampoco pretende obliterar las complejas relaciones que pudieran generarse en diversas coyunturas históricas entre los mundos del amo y del esclavo. La idea de "muerte social" subraya una particular óptica legitimadora, no las fisuras en las complejas prácticas socio-culturales de la esclavitud.
} 
sin rodeos: "acuerdese smd. cuando lea qe. yo soy esclavo y qe. el esclavo es un ser muerto ante su señor" (Manzano 84). Pero muerto ante su señor, precisa el texto, especificando quién es el sujeto de la mirada y relativizando (con un discreto sesgo contestatario) la soberanía de esa percepción.

$\mathrm{Si}$ de los muertos inmortalizados en las biografías se pretendía un rendimiento simbólico, del "muerto social" en la plantación se exigía un rendimiento material. En tanto "muerto social", el esclavo era (re)querido como una suerte de vacío instrumentalizable. Despojado de subjetividad legítima por la racionalidad del poder, vino a ser considerado como parte del "equipo" productivo, un instrumento a utilizar e intercambiar.

Considerado como equipo, el esclavo perdió significación humana. Estaba desprovisto de personalidad. Por eso su nacimiento o muerte, o su compra y venta, se anotan en el libro de contabilidad como entrada o salida de un activo [...] Como a cualquier otro equipo, también a los negros se les calculó su depreciación que, en los años de máxima barbarie, se estimó en un $10 \%$ anual; hacia la década de 1840 se calculó en un $5 \%$ y, después en la segunda mitad del siglo se computó en un $3 \%$ (Moreno, El Ingenio, vol. II 15). ${ }^{14}$

Subvertir esa condición cosificada e instrumental era el sentido más profundo de toda forma de resistencia a la esclavitud. Cuando los esclavos en sus rituales nocturnos, en un paréntesis de sus jornadas de trabajo a destajo, y en el frenesí incontenible del toque de tambor, desafiaban -en mancomunidad alegre o temerosa, pero siempre viva, con sus muertos- la coacción a un no ser, se desataba la ansiedad y el desconcierto de los amos. Ante esa esfera cultural subalterna, distinta e inaccesible, recorrida por otro tipo de intercambios simbólicos y materiales, el amo reconocería con desasosiego otra energía vital potencialmente incontrolable. Cercado por ese mundo, en donde los muertos no comportaban la forma de una inmortalidad instrumental sino la de agentes de una misteriosa reciprocidad activa, el sujeto del poder, cuya faz se reflejaba gozosa en la monumentalidad inmóvil de los muertos útiles, habría también de intuir angustiadamente el acecho de sus propias sombras. Y fuera tal vez posible que con otros tonos musitara para sí aquella frase que más de un siglo después pronunciara impasible Bataille: "Mi muerte en todas partes, mi muerte que sueña".

\section{OBRAS CITADAS}

Actas de la Sociedad Patriótica de la Havana. Junta Ordinaria del 17 de octubre de 1793 y Junta del 24 de julio de 1794 (manuscritas).

Arango, Arturo. "Otra teleología de la racionalidad cubana". Casa de las Américas 194 (enero-marzo 1994): 108-113.

\footnotetext{
${ }^{14}$ Del "costo" del equipo dependía el cuidado y uso que se le diera. En el caso del período que va de 1789 a 1820 (momento de emergencia y consolidación de la sacarocracia), se trató de una época caracterizada por esclavos baratos y azúcar cara (Moreno, El Ingenio, vol. II 26). De modo que resultaba más rentable económicamente intensificar hasta el límite la productividad del esclavo, aunque ello significara agotar su existencia. Una existencia que, de cualquier modo, no se le reconocía como propia.
} 
Bachiller y Morales, Antonio. Apuntes para la historia de las letras y la instrucción pública en la isla de Cuba. Tres tomos. [1859, 1860, 1861 respectivamente]. La Habana: Cultural S.A., 1936.

Baudrillard, Jean. El intercambio simbólico y la muerte [1976]. Trad. Carmen Rada. Caracas: Monte Ávila, 1993.

Barthes, Roland. "El discurso de la historia". José Sazbón, ed. Estructuralismoyliteratura. Buenos Aires: Edición Nueva Visión, 1970. 37-50.

BenítezRojo, Antonio. "Power/Sugar/Literature: Toward a Reinterpretation of Cubanness". Cuban Studies/Estudios Cubanos 16 (1986): 9-31.

Boswell, John. Life of Johnson [1791]. Oxford: Oxford University Press, 1987.

Carlyle, Thomas. On Heroes, Hero Worship and the Heroic in History [1841]. Lincoln/ London: University of Nebraska Press, 1966.

Cepero Bonilla, Raúl. Azúcar y abolición. Apuntes para una historia crítica del abolicionismo. La Habana: Editorial Cenit, 1948.

de Certeau, Michel. La escritura de la historia. México: Universidad Iberoamericana, 1985.

Emerson, Ralph Waldo. Representative Men. Seven Lectures [1850]. Boston/NY: Houghton Mifflin, 1893.

Habermas, Jürgen. "La modernidad, un proyecto incompleto" [1980]. Recogido en Hal Foster (ed.). La posmodernidad. Trad. Jordi Fibla. México: Colofón, 1988. 19-36.

Knight, Franklin. Slave Society in Cuba during the Nineteenth Century. Madison: University of Wisconsin Press, 1970.

Manzano, Juan Francisco. Autobiografia, cartas y versos de Juan Francisco Manzano. Con un estudio preliminar por José Luciano Franco. La Habana: Municipio de La Habana, 1937.

Martí, José. Obras completas. Vol. 13. La Habana: Editorial Nacional de Cuba, 1964. Marx, Karl. El capital. Tomo I, Vol. I [1867]. México: Siglo XXI, 1978.

Memorias de la Sociedad Patriótica. Havana: Imprenta de la Capitanía General, 1793 y 1794.

Michelet, Jules. Jeanne d'Arc et autres textes. Paris: Gallimard, 1974.

Miller, Toby. The Well-Tempered Self. Citizenship, Culture and the Postmodern Subject. Baltimore: The Johns Hopkins University Press, 1993.

Montoro, Rafael y Adrián del Valle. Compendio de la historia de la Sociedad Económica Amigos del País de La Habana. La Habana: Imprenta y Librería "El Universo", 1930.

Moreno Fraginals, Manuel. Cuba/España. España/Cuba. Historia común. Barcelona: Editorial Crítica, 1995.

"Desgarramiento azucarero e integración nacional". Casa de las Américas XI:62 (1970): 6-22.

El ingenio. El complejo económico social cubano del azúcar. 3 tomos. La Habana: Editorial de Ciencias Sociales, 1978.

Nietzsche, Friedrich. The Use and Abuse of History [1874]. Indianapolis: Bobbs-Merrill Educational Publishing, 1957.

Patterson, Orlando. Slavery and Social Death. A Comparative Study. Cambridge: Harvard University Press, 1982. 
Papel Periódico de la Havana, núm. 87, año de 1793.

Rojas, Rafael. "El epitafio de Saco". La Gaceta de Cuba 34:1 (enero-febrero 1996): 1418.

"La otra moral de la teleología cubana". Apuntes Posmodernos/Post-Modern Notes (Primavera 1994): 44-54. Reproducido en Casa de las Américas 194, 1994.

"Viaje a la semilla: Instituciones de la anti-modernidad cubana". Apuntes Posmodernos/Post-Modern Notes 4:1 (1993): 3-20.

Romay, Tomás. Discurso Premiado por la Sociedad Patriótica de la Havana, en Junta que Celebró el Día 24 de Julio del Año 1794. La Havana: Imprenta de la Capitanía General, 1794.

Obras Completas, vol. II. José López Sánchez (ed.). La Habana: Academia de Ciencias de la República de Cuba. Museo Histórico de las Ciencias Médicas "Carlos Finlay", 1966.

Sarmiento, Domingo Faustino. Facundo [1845]. Buenos Aires: Losada, 1963.

Scott, Rebecca. Slave Emancipation in Cuba. The Transition to Free Labor, 1860-1899. Princeton: Princeton University Press, 1985.

Torres-Cuevas, Eduardo. "Apología de nuestra historia" Partes I y II. Contracorriente 1 y 2 (enero-agosto y septiembre-diciembre 1995).

Vitier, Cintio. "Comentarios a dos ensayos sobre axiología cubana". Casa de las Américas 194 (enero-marzo 1994): 96-107.

Ese sol del mundo moral. Para una historia de la eticidad cubana. México: Siglo XXI, 1975.

Vitier, Medardo. Las ideas en Cuba. 2 tomos. La Habana: Editorial Trópico, 1938.

Weber, Max. General Economic History. Trad. H. P. Secher. New York: Collier Books, 1961. 